\title{
The increase of plasminogen activator inhibitor activity is associated with graft occlusion in patients undergoing aorto-coronary bypass surgery
}

\author{
J. Rifón, ${ }^{1}$ J. A. Páramo, ${ }^{1,2}$ C. Panizo, ${ }^{1}$ R. Montes $^{2}$ and E. Rocha ${ }^{1,2}{ }^{1}$ Haematology Service, Clínica Universitaria, \\ and ${ }^{2}$ Laboratory of Vascular Biology and Thrombosis, School of Medicine, University of Navarra, Pamplona, Spain
}

Received 7 March 1997; accepted for publication 1 August 1997

\begin{abstract}
Summary. Early graft occlusion is a common complication in patients undergoing aorto-coronary bypass surgery. Both mechanical and haemostatic factors play a role in the pathogenesis of thrombotic occlusion. Several studies have demonstrated a relationship between fibrinolytic activity and venous or arterial thrombosis. We undertook this study to evaluate the possible contribution of the fibrinolytic system to postoperative occlusion in patients undergoing aortocoronary bypass graft (CABG).

A venous occlusion (VO) test was performed preoperatively in 82 patients undergoing revascularization procedures. Before and after VO the euglobulin fibrinolytic activity and tissue type plasminogen activator (t-PA) activity and antigen were measured. Plasminogen activator inhibitor (PAI) activity and antigen and fibrinogen were also assessed in
\end{abstract}

the preocclusion sample. An angiography performed $10 \mathrm{~d}$ postoperatively showed graft occlusion in $23 \%$ of patients. Patients with graft occlusion had significantly higher preoperative PAI activity than patients without occlusion $(P<0 \cdot 001)$. Reduced fibrinolytic response and t-PA capacity was also observed in the group of patients with graft occlusion $(P<0.03$ and $P<0.02$ respectively).

We found a reduced preoperative fibrinolytic response, mainly related to high plasma PAI activity in patients with postoperative graft occlusion. These results suggest that increased PAI activity might have a predictive value for early thrombosis in patients undergoing CABG.

Keywords: aortocoronary bypass, thrombosis, fibrinolysis, PAI-1.
Graft thrombotic occlusion is a common complication in patients undergoing aortocoronary bypass surgery (CABG). Angiographically proven occlusion rates within a month after operation are approximately $20 \%$ for all types of vein grafts and about 5\% when an internal mammary artery is used. The occlusion rate per patient with one or more distal anastomoses occluded in the same period ranged from $21 \%$ to $38 \%$ (Hutchings, 1980; Fuster \& Chesebro, 1986).

Experimental studies revealed an early phase of thrombotic occlusion, starting in the postoperative period (Chesebro et al, 1986). Known risks factors for early occlusion include low graft blood flow, small luminal size of the grafted vessels, endarterectomy, local atheroma at the arteriotomy site, elevated serum lipids and smoking (Lytle et al, 1985).

Platelets play a pivotal role in the pathogenesis of early graft occlusion. Vein grafts are vulnerable to endothelial damage which may occur by handling during the operation

Correspondence: Dr E. Rocha, Haematology Service, Clínica Universitaria, School of Medicine, University of Navarra, P.O. Box 4209, 31080 Pamplona, Spain. and by sudden exposure to the high-pressure pulsatile arterial system. Platelet deposition occurs in areas of endothelial damage and the consequent release of platelet factors initiates mural or occlusive thrombus formation that begins during the operation (Barboriak et al, 1978; Falk, 1989).

Since fibrin is an important structural component of thrombi, and the fibrinolytic system contributes to the clearance of fibrin from the circulation (Collen \& Lijnen, 1991), it can be assumed that the integrity of fibrinolytic mechanisms is a prerequisite for graft permeability. In fact, several authors have convincingly demonstrated a relationship between fibrinolytic activity and either venous or arterial thrombosis (Páramo et al, 1985a; Nilsson et al, 1985; Aznar et al, 1988; Rocha et al, 1988; Engesser et al, 1989). A previous study has also suggested that the impairment of the fibrinolytic system before surgery may play an important role in the pathogenesis of early coronary graft occlusion after revascularization procedures (Arnesen et al, 1983), but it was performed using nonsensitive assays for the different components. 
In this study the fibrinolytic potential in patients undergoing CABG was assessed by measuring the preoperative fibrinolytic response to venous occlusion as well as the plasma concentration of fibrinolysis activators and inhibitors, using highly sensitive assays, and results were correlated with postoperative graft occlusion.

\section{PATIENTS AND METHODS}

Patients. The study was carried out in 82 patients consecutively admitted for elective aorto-coronary bypass operations because of severe stable angina pectoris. There were 76 males and six females with a mean age of $59 \pm 9$ years. The exclusion criteria were: valvular heart disease, emergency surgery and patients undergoing a different surgical procedure simultaneously such as ventricular aneurismectomy or valvuloplasty. None of the patients received anticoagulant or corticosteroid medication. Oral antiplatelet agents had been discontinued a week before the operation. All patients received standard antithrombotic prophylaxis with dipyridamole $(225 \mathrm{mg} / \mathrm{d})$ starting immediately before surgery and aspirin $(250 \mathrm{mg} / \mathrm{d})$ plus dipyridamole throughout the postoperative period.

In all cases the surgery was carried out with extracorporeal circulation, hypothermia and haemodilution. The 82 patients received a total of 216 grafts (mean 2.6 grafts per patient). The saphenous vein was used in $136(63 \%)$ and the internal mammary artery used in 80 cases $(37 \%)$. Only one patient died within the $15 \mathrm{~d}$ following the operation.

The following risk factors for coronary disease were considered: smoking, hypercholesterolaemia, hypertension, and diabetes mellitus.

A group of 30 age-matched healthy subjects served as a reference population for control values.

Blood sampling. Blood samples were drawn by venepuncture between 8.00 and 9.30 a.m. after the subjects had rested in the supine position for $10 \mathrm{~min}$ and again after venous stasis produced by a tourniquet applied to the upper arm inflated to a pressure of $100 \mathrm{mmHg}$ (between systolic and diastolic pressures) for $10 \mathrm{~min}$. Samples were taken at least $2 \mathrm{~h}$ before surgery. No acute episode of coronary insufficiency was present at the time of blood collection. Preand postocclusion blood was collected into $0 \cdot 13 \mathrm{M}$ trisodium citrate in a ratio $9: 1$, centrifuged at $2000 \mathrm{~g}$ for $20 \mathrm{~min}$ at $4^{\circ} \mathrm{C}$ and the platelet-poor plasma was stored at $-70^{\circ} \mathrm{C}$.

To measure t-PA activity, $1 \mathrm{ml}$ of citrated whole blood was acidified by mixing with $1 \mathrm{ml}$ of acetate buffer $(0 \cdot 2 \mathrm{M}, \mathrm{pH}$ 3.9). This was immediately centrifuged at $2000 \mathrm{~g}$ for $15 \mathrm{~min}$, and $0.6 \mathrm{ml}$ of supernatant were further acidified by the addition of $40 \mu \mathrm{l}$ of $1 \mathrm{M} \mathrm{HCl}$ and then frozen at $-70^{\circ} \mathrm{C}$.

Methods. Before and after VO the following parameters were measured: (i) Euglobulin fibrinolytic activity (EFA) on fibrin plates. Euglobulin fractions for fibrin plates were prepared by mixing $0.5 \mathrm{ml}$ of plasma with $4.5 \mathrm{ml} 0.025 \%$ chilled acetic acid, incubated on ice for $15 \mathrm{~min}$ and then centrifuged at $1000 \mathrm{~g}$ for $10 \mathrm{~min}$ at $4^{\circ} \mathrm{C}$. The precipitate was then resuspended in $0.5 \mathrm{ml}$ phosphate-buffered saline. This fraction was applied to fibrin plates in triplicate and the diameter of the area of lysis measured after $18 \mathrm{~h}$ at $37^{\circ} \mathrm{C}$
(Kluft et al, 1976). Results were expressed as $\mathrm{U} / \mathrm{ml}$ by reference to a standard curve produced using the International standard for t-PA (ref. 86/679, kindly provided by Dr Gaffney, NIBSC, London). The fibrinolytic response was defined as the difference between postocclusion and preocclusion values of EFA as described by Stalder et al (1985). (ii) t-PA activity was measured in acidified plasma samples by an amidolytic microtitre assay (Coatest t-PA, KabiVitrum, Stockholm, Sweden). t-PA activity release was defined as the difference between activity before venous occlusion and the activity after venous occlusion. (iii) The level of t-PA antigen was determined by an ELISA assay using a monoclonal antibody against t-PA with a commercially available kit (tintElize t-PA from Biopool, Sweden) (Korninger et al, 1986). t-PA antigen release was calculated as the difference between postocclusion and preocclusion values of t-PA Ag (Hamsten et al, 1985).

Before VO the following parameters were also determined: (i) PAI activity was measured by adding a certain ammount of t-PA to diluted plasma and determining residual t-PA activity as described by Chmielewska et al (1983). Inhibitor activity was expressed in units of plasminogen activator inhibited per ml. (ii) PAI-1 antigen was determined by an ELISA assay essentially as described by Declerk et al (1988) using a monoclonal antibody against PAI-1 (tintElize PAI-1 from Biopool, Sweden). (iii) Fibrinogen was measured by the Clauss (1957) method. (iv) Whole serum cholesterol, HDL and LDL-cholesterol and triglycerides were measured by standard enzymatic methods.

Angiographic analysis. Selective shunt angiography using the Judkins technique was performed in all patients on postoperative day 10 to evaluate the permeability of coronary grafts. The angiographic results were analysed by an independent team who were unaware of the fibrinolysis findings. The results were classified as total occlusion in at least one graft or no occlusion.

Statistical analysis. Results are expressed as mean \pm SD. Since the values were not distributed normally, the MannWhitney test after log transformation was used for group comparison. For group differences regarding the fibrinolytic potential, the exact Fisher test was used. A $P$ value $<0 \cdot 05$ was considered to be significant.

\section{RESULTS}

Eighty-two patients undergoing CABG were included in this study. Angiographically proven graft occlusion was demonstrated in 19 patients (23\%). Table I shows the total number and the type of graft. The global rate of graft occlusion was

Table I. Graft occlusion in relation to type of graft.

\begin{tabular}{lrrr}
\hline & No. of grafts & \multicolumn{2}{l}{ Occluded } \\
\hline Saphenous vein & 136 & 22 & $(16 \cdot 1 \%)$ \\
Mammary artery & 80 & 3 & $(3 \cdot 7 \%)$ \\
Total grafts & 216 & 25 & $(11 \cdot 5 \%)$ \\
\hline
\end{tabular}




\section{J. Rifón et al}

$11 \cdot 5 \%$ and it was significantly higher for saphenous grafts $(16 \cdot 1 \%)$ as compared to mammary artery grafts $(3 \cdot 7 \%)$ $(P<0 \cdot 0001)$

General assessment and risk factors evaluation

As shown in Table II, no significant differences with regard to age, diabetes, hypercholesterolaemia, including both HDL and LDL cholesterol, hypertriglyceridaemia, hypertension and smoking were observed in patients with graft occlusion when compared to those without graft occlusion. Although the rate of graft occlusion was higher in women than in men $(50 \% \vee 21 \%)$, this difference was not significant due to the small number of women included.

Table II. Baseline characteristics, risk factors and biochemical profile.

\begin{tabular}{lcc}
\hline & $\begin{array}{c}\text { Patients without } \\
\text { occlusion }(n=63)\end{array}$ & $\begin{array}{c}\text { Patients with } \\
\text { occlusion }(n=19)\end{array}$ \\
\hline Age & $58 \cdot 0 \pm 9 \cdot 0$ & $59 \cdot 2 \pm 9 \cdot 6$ \\
Sex (M/F) & $60 / 3$ & $16 / 3$ \\
Diabetes & $9(14 \%)$ & $2(11 \%)$ \\
Hypertension & $28(44 \%)$ & $9(47 \%)$ \\
Smoking & $39(62 \%)$ & $10(53 \%)$ \\
Cholesterol $(\mathrm{mmol} / \mathrm{l})$ & $5 \cdot 72 \pm 0.98$ & $5 \cdot 37 \pm 1 \cdot 06$ \\
Triglycerides $(\mathrm{mmol} / \mathrm{l})$ & $1 \cdot 63 \pm 0 \cdot 61$ & $1.65 \pm 0.53$ \\
HDL-cholesterol $(\mathrm{mmol} / \mathrm{l})$ & $0 \cdot 90 \pm 0 \cdot 33$ & $0 \cdot 84 \pm 0 \cdot 20$ \\
LDL-cholesterol $(\mathrm{mmol} / \mathrm{l})$ & $4 \cdot 22 \pm 0.92$ & $3.91 \pm 0 \cdot 88$ \\
& & \\
\hline
\end{tabular}

Baseline fibrinolytic activity in patients with and without graft occlusion

Preoperatively, no differences for the fibrinolysis parameters analysed were observed in the group of patients compared to healthy subjects (not shown), except for the concentrations of PAI, both functional and antigen, which were significantly higher $(P<0 \cdot 001)$ in the group of patients $(12.5 \pm 8 \cdot 8 \mathrm{U} / \mathrm{ml}$ and $30 \cdot 7 \pm 19 \cdot 6 \mathrm{ng} / \mathrm{ml})$ than in controls $(6 \cdot 5 \pm 4 \cdot 8 \mathrm{U} / \mathrm{ml}$ and $12.9 \pm 9.6 \mathrm{ng} / \mathrm{ml}$ )

Table III shows the preoperative fibrinolysis parameters before and after $\mathrm{VO}$ in relation to the postoperative

Table III. Fibrinolytic parameters before venous occlusion (VO) in patients with and without graft occlusion. Mean \pm SD is reported.

\begin{tabular}{lccl}
\hline & $\begin{array}{l}\text { Patients without } \\
\text { occlusion } \\
(n=63)\end{array}$ & $\begin{array}{l}\text { Patients with } \\
\text { occlusion } \\
(n=19)\end{array}$ & $P$ \\
\hline EFA $(\mathrm{U} / \mathrm{ml})$ & $0 \cdot 8 \pm 0 \cdot 9$ & $1 \cdot 0 \pm 1 \cdot 2$ & $\mathrm{NS}$ \\
t-PA activity $(\mathrm{U} / \mathrm{ml})$ & $2 \cdot 1 \pm 1 \cdot 2$ & $1 \cdot 9 \pm 1 \cdot 0$ & $\mathrm{NS}$ \\
t-PA antigen $(\mathrm{ng} / \mathrm{ml})$ & $7 \cdot 1 \pm 3 \cdot 7$ & $7 \cdot 8 \pm 5 \cdot 5$ & $\mathrm{NS}$ \\
PAI activity $(\mathrm{U} / \mathrm{ml})$ & $10 \cdot 8 \pm 7 \cdot 6$ & $20 \cdot 9 \pm 10 \cdot 1$ & $<0 \cdot 001$ \\
PAI-1 antigen $(\mathrm{ng} / \mathrm{ml})$ & $30 \cdot 1 \pm 18 \cdot 0$ & $34 \cdot 1 \pm 26 \cdot 2$ & $\mathrm{NS}$ \\
Fibrinogen $(\mathrm{g} / \mathrm{l})$ & $3 \cdot 5 \pm 0 \cdot 7$ & $3 \cdot 8 \pm 0 \cdot 9$ & $\mathrm{NS}$ \\
\hline
\end{tabular}

NS: not significant.

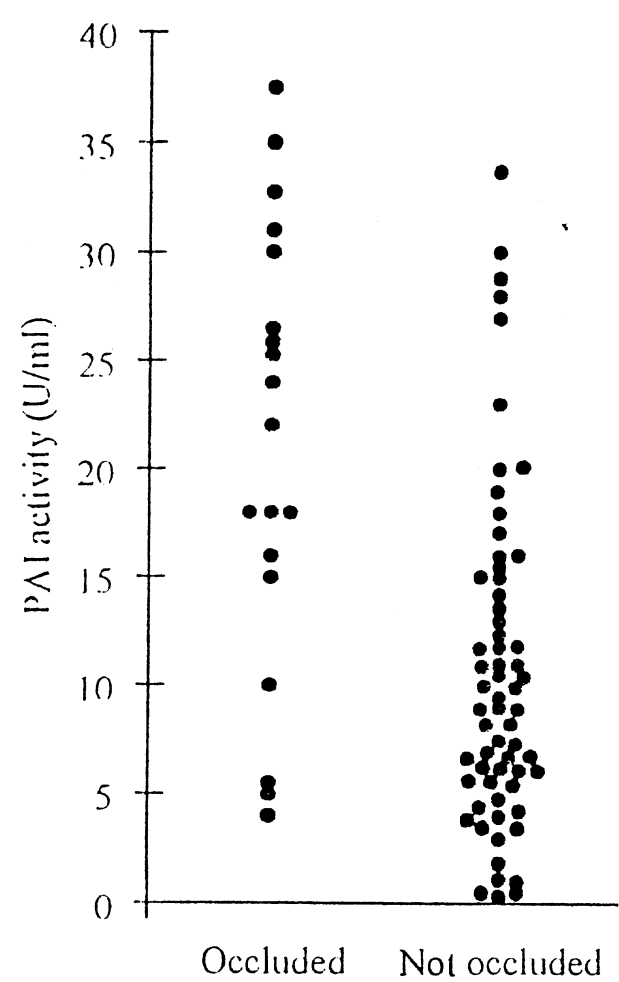

Fig 1. Scatterplot showing individual distribution of preoperative plasma PAI-1 levels in patients with and without postoperative graft occlusion.

angiographic findings. The mean plasma PAI-1 activity was significantly higher in patients with postoperative graft occlusion $(20 \cdot 9 \pm 10 \cdot 1 \mathrm{U} / \mathrm{ml}, 95 \%$ CI $16 \cdot 0-25 \cdot 8)$ than in those without graft occlusion $(10 \cdot 8 \pm 7 \cdot 6,95 \%$ CI $8 \cdot 9-$ $12 \cdot 7)(P<0 \cdot 001)$. Fig 1 shows the distribution of PAI- 1 activity in both patient groups. $13 / 19$ patients with graft occlusion $(68 \%)$, but only $13 / 63$ patients $(20 \%)$ without graft occlusion, had plasma levels of PAI-1 higher than the mean \pm 2 SD of normal values.

No differences in the distribution of other haemostatic fibrinolysis parameters analysed before venous occlusion were observed between groups.

Postocclusion fibrinolysis parameters in patients with and without graft occlusion

After venous occlusion, EFA was significantly lower in patients with graft occlusion $(1 \cdot 7 \pm 1 \cdot 5 \mathrm{U} / \mathrm{ml} v$ $3 \cdot 8 \pm 5 \cdot 0 \mathrm{U} / \mathrm{ml}, P<0 \cdot 05)$. t-PA activity was significantly reduced in this group, compared to patients without graft occlusion $(4 \cdot 7 \pm 3.4 \mathrm{U} / \mathrm{ml} \vee 9 \cdot 1 \pm 7 \cdot 6 \mathrm{U} / \mathrm{ml}, \quad P<0 \cdot 001)$, whereas t-PA antigen concentration was similar between the groups $(18 \cdot 4 \pm 14 \cdot 8 \mathrm{ng} / \mathrm{ml} v 19 \cdot 3 \pm 14 \cdot 0 \mathrm{ng} / \mathrm{ml})$.

In order to establish which of the fibrinolysis parameters was best associated with early graft occlusion we calculated the fibrinolytic response, t-PA activity release and t-PA antigen release in both patient groups. As shown in Table IV, the fibrinolytic response and t-PA activity release were significantly reduced in patients with postoperative graft occlusion $(P<0.03$ and $P<0.02$ respectively), whereas the 
Table IV. Fibrinolytic potential after VO in patients with and without graft occlusion. Mean \pm SD is reported.

\begin{tabular}{lccc}
\hline & Non-occluded & Occluded & $P$ \\
\hline Fibrinolytic response $(\mathrm{U} / \mathrm{ml})$ & $3 \cdot 0 \pm 4 \cdot 5$ & $0 \cdot 7 \pm 0 \cdot 6$ & $<0 \cdot 03$ \\
t-PA activity release $(\mathrm{U} / \mathrm{ml})$ & $7 \cdot 0 \pm 7 \cdot 3$ & $2 \cdot 8 \pm 2 \cdot 6$ & $<0 \cdot 02$ \\
t-PA antigen release $(\mathrm{ng} / \mathrm{ml})$ & $12 \cdot 2 \pm 13 \cdot 0$ & $10 \cdot 6 \pm 14 \cdot 2$ & $\mathrm{NS}$ \\
\hline
\end{tabular}

NS: not significant.

$\mathrm{t}$-PA antigen release showed no differences between groups. When analysing the PAI-1 levels in patients with either low fibrinolytic response and/or t-PA activity release we found significantly higher (mean $+2 \mathrm{SD}$ ) levels in $29 / 33$ of these patients $(87 \cdot 8 \%)$ which indicated that increased PAI activity was the main cause of the low fibrinolytic response in this group. In the 33 patients with low fibrinolytic potential the graft occlusion rate was $45 \%$ $(15 / 33)$, compared to $8 \%(4 / 49)$ in the remaining patients.

\section{DISCUSSION}

This study showed that a low preoperative fibrinolytic potential, mainly due to high PAI-1 levels, significantly contributed to early graft occlusion in patients undergoing CABG. In our series the rate of graft occlusion $(23 \%)$ was higher for saphenous grafts than for mammary artery grafts, which is in agreement with previous reports (Chesebro et al, 1986). This difference could be explained by the anatomical and physiological characteristics of grafts.

Different studies have indicated that an impairment of both coagulation and fibrinolysis are implicated in coronary heart disease (Hamsten, 1993). It remains to be ascertained whether disturbances of haemostatic function predispose to early graft occlusion. In a previous report we demonstrated that the preoperative increase of thrombin-antithrombin complexes was higher in patients with graft occlusion than in those with graft patency, suggesting that a greater generation of thrombin before surgery can be an important factor in the development of thrombosis after CABG (Rifón et al, 1994). Studies on fibrinolytic function in connection with surgery have been conducted mainly in patients undergoing abdominal or orthopaedic surgery, emphasizing the existence of a postoperative fibrinolytic shutdown secondary to increased PAI activity (Páramo et al, 1985a; D’Angelo et al, 1985; Kluft et al, 1986; Rocha et al, 1988). Few clinical studies have addressed the preoperative fibrinolytic function in patients subjected to CABG. Arnessen et al (1983) showed low preoperative fibrinolytic activity to be associated with graft occlusion. More recently, Moor et al (1994) examined the time course of individual fibrinolytic components in a small series of patients showing weak associations with the presence of graft occlusion.

We have determined the fibrinolytic response to venous occlusion in a large series of patients undergoing CABG.
When compared to a control group we found significantly higher PAI activity in the study population, confirming previous reports of an association between coronary artery disease and high PAI levels (Páramo et al, 1985b; Thompson et al, 1993; Rocha \& Páramo, 1994).

Basal PAI activity was significantly higher in patients with graft occlusion compared to those with graft patency, whereas no differences in other fibrinolysis parameters analysed were observed. After VO a lower increase of EFA and t-PA activity was observed in patients with graft occlusion. Consequently the fibrinolytic response and t-PA activity release were significantly lower in patients with graft occlusion. The plasma PAI-1 activity in patients with low fibrinolytic potential (either low fibrinolytic response and/or low t-PA activity release) was significantly higher than in those with normal fibrinolytic potential, thus indicating that PAI-1 is main cause of fibrinolysis impairment. The fact that only PAI activity differed whereas both PAI-1 and t-PA antigen were similar in patients with and without graft occlusion could be due to the different origin of PAI-1 (endothelial cells, platelets, etc.) although an interference of other inhibitors cannot be ruled out.

Alterations in the balance between the coagulation and the fibrinolysis mechanisms can play an important role for the development of thrombosis within the arterial vessels. Of importance is the pathophysiological role of hypercoagulability (increase of fibrinogen and factor VII) and deficient fibrinolysis (mainly related to high PAI-1) in patients with coronary disease (Hamsten, 1993; Fuster et al, 1992). Mean fibrinogen levels were slightly higher in patients with graft occlusion, but this difference was not significant in our study. Likewise, the fact that lipid concentrations were similar between groups suggest that they do not contribute significantly to early graft occlusion. It must be emphasized, however, that the lipoprotein(a) level, not measured in our samples, has been found to be a predictor of stenosis after CABG (Hoff et al, 1990).

Several considerations can be made regarding the association between the accelerated thrombotic disease and PAI activity elevation. The association may be a reflection of an underlying process responsible for increased PAI, such as the insulin resistance syndrome (Juhan-Vague et al, 1989, 1993; Schneider et al, 1993). In our population the insulin levels were not determined and so the presence or absence of insulin resistance was not assessed, but the proportion of diabetic patients was similar in the two groups. Likewise, no differences in the triglyceride levels were observed between patients with or without graft occlusion. Alternatively, the possibility that PAI elevation affects the progression of vascular disease in patients predisposed to accelerated atherosclerosis and restenosis should also be considered (Fujii et al, 1992). Finally, the association may be causal but attributable to changes in the vessel wall involving expression of fibrinolytic proteins associated with eleboration of excessive amounts of PAI-1. The possibility of measuring PAI-1 expression in the saphenous veins might also be considered in the light of the role of local expression in atherosclerosis (Schneiderman et al, 1992). 


\section{J. Rifón et al}

In conclusion, we have shown that low preoperative fibrinolytic activity, related to high PAI activity, may play a significant role for early graft occlusion in patients undergoing CABG. Whether PAI activity is also a marker for late graft occlusion needs to be evaluated. The possibility of reducing PAI activity levels may represent another approach to be taken into consideration to prevent graft thrombosis related to revascularization procedures.

\section{ACKNOWLEDGMENT}

This work was suported by a grant $89 / 0448$ from the FIS of the Ministerio de Sanidad, Spain.

\section{REFERENCES.}

Arnessen, H., Semb, G., Hol, R. \& Karlsen, H. (1983) Fibrinolytic capacity after venous stasis in patients undergoing aorto-coronary bypass surgery: relation to shunt occlusion. Scandinavian Journal of Haematology, 30, (Suppl. 39), 43-46.

Aznar, J., Estellés, A., Tormo, G., Sapena, P., Blanch, S. \& España, F. (1988) Plasminogen activator inhibitor activity and other fibrinolytic variables in patients with coronary artery disease. British Heart Journal, 59, 535-541.

Barboriak, J.J., Pintar, K., Van Horn, D.L., Batayias, G.E. \& Korus, M.E. (1978) Pathologic findings in the aortocoronary vein grafts: a scanning electron microscopy study. Atherosclerosis, 29, 69-80.

Chesebro, J.H., Lam, J.Y.T. \& Fuster, V. (1986) The pathogenesis and prevention of aorto-coronary vein bypass graft occlusion and restenosis after arterial angioplasty: role of vascular injury and platelet thrombus deposition. Journal of the American College of Cardiology, 8, 58b-66b.

Chmielewska, J., Ranby, M. \& Wiman, B. (1983) Evidence for a rapid inhibitor to tissue plasminogen activator in plasma. Thrombosis Research, 31, 427-436.

Clauss, A. (1957) Gerinnungsphysiologische Schnellmethode zur Bestimmung des Fibrinogens. Acta Haematologica, 17, 237-246.

Collen, D. \& Lijnen, H.R. (1991) Basic and clinical aspects of fibrinolysis and thrombolysis. Blood, 78, 3114-3124.

D’Angelo, A., Kluft, C., Verheijen, J.H., Rijken, D.C., Mozzi, E. \& Mannucci, P.M. (1985) Fibrinolytic shut-down after surgery: impairment of the balance between tissue-type plasminogen activator and its specific inhibitor. European Journal of Clinical Investigation, 15, 308-312.

Declerck, P.J., Alessi, M.C., Verstraete, M., Kruithof, E.K.O., JuhanVague, I. \& Collen, D. (1988) Measurement of plasminogen activator inhibitor 1 in biological fluids with a murine monoclonal antibody-based enzyme-linked immunosorbent assay. Blood, 71, 220-225.

Engesser, L., Brommer, E.J.P., Kluft, C. \& Briët, E. (1989) Elevated plasminogen activator inhibitor (PAI), a cause of thrombophilia? A study in 203 patients with familial or sporadic venous thrombophilia. Thrombosis and Haemostasis, 62, 673-680.

Falk, E. (1989) Morphologic features of unstable atherothrombotic plaques underlying acute coronary syndromes. American Journal of Cardiology, 63, 114E-120E.

Fujii, S., Sawa, H., Safitz, J.E., Lucore, C.L. \& Sobel, B.E. (1992) Induction of endothelial cell expression of the plasminogen activator inhibitor type 1 gene by thrombosis in vivo. Circulation, 86, 2000-2010.

Fuster, V., Badimon, L., Badimon, J.J. \& Chesebro, J.H. (1992) The pathogenesis of coronary artery disease and the acute coronary syndromes (second of two parts). New England Journal of Medicine, 326, 310-318.

Fuster, V. \& Chesebro, J.H. (1986) Role of platelets and platelet inhibitors in aorto-coronary artery vein graft disease. Circulation, 73, 227-232.

Hamsten, A. (1993) The hemostatic system and coronary heart disease. Thrombosis Research, 70, 1-38.

Hamsten, A., Wiman, B., De Faire, V. \& Blombäck, H. (1985) Increased plasma levels of a rapid inhibitor of tissue plasminogen activator in young survivors of myocardial infarction. New England Journal of Medicine, 313, 1557-1563.

Hoff, H.F., Beck, G.J., Skibinski, C.I., Jurgens, G., O’Neil, J., Kramer, J. \& Lytle, B. (1990) Serum Lp(a) level as a predictor of vein graft stenosis after coronary artery bypass surgery in patients. Circulation, 82, 1046-1048.

Hutchings, G.M. (1980) Pathological changes in aortocoronary bypass grafts. Annual Review of Medicine, 31, 289-301.

Juhan-Vague, I., Roul, C., Alessi, M.C., Ardissone, J.P., Heim, M. \& Vague, P. (1989) Increased plasminogen activator inhibitor activity in non insulin dependent diabetic patients: relations with plasma insulin. Thrombosis and Haemostasis, 61, 370-373.

Juhan-Vague, Y., Thompson, S.G. \& Jespersen, J., on behalf of the ECAT Angina Pectoris Study Group (1993) Involvement of the hemostatic system in the insulin resistance syndrome: a study of 1500 patients with angina pectoris. Arteriosclerosis and Thrombosis, 13, 1865-1873.

Kluft, C., Brakman, P. \& Veldhuyzen-Stolk, E.C. (1976) Screening of fibrinolytic activity in plasma euglobulin fractions on the fibrin plate. Progress in Chemical Fibrinolysis, Vol. 2 (ed. by J. F. Davidson, M. M. Samama and P. C. Desnooyers), pp. 57-65. Raven Press, New York.

Kluft, C., Jie, A.H.H. \& Lowe, G.D.O. (1986) Association between postoperative hyper-response in t-PA inhibition and deep vein thrombosis. Thrombosis and Haemostasis, 56, 107.

Korninger, C., Speizer, W., Wojta, J. \& Binder, B.R. (1986) Sandwich ELISA for t-PA antigen employing a monoclonal antibody. Thrombosis Research, 41, 527-535.

Lytle, B.W., Loop, F.D., Cosgrove, D.M., Ratliff, N.B, Easley, K. \& Taylor, P.C. (1985) Long-term (5-12 years) serial studies of internal mammary artery and saphenous vein coronary bypass grafts. Journal of Thoracic and Cardiovascular Surgery, 89, 248-258.

Moor, E., Hamsten, A., Blombäck, M., Herzfeld, Y., Wiman, B. \& Ryden, L. (1994) Haemostatic factors and inhibitors and coronary artery bypass grafting: preoperative alterations and relations to graft occlusion. Thrombosis and Haemostasis, 72, 335-342.

Nilsson, I.M., Ljungner, H. \& Tengborn, L. (1985) Two different mechanisms in patients with venous thrombosis and defective fibrinolysis: low concentraction of plasminogen activator or increased concentration of plasminogen activator inhibitor. British Medical Journal, 290, 1453-1455.

Páramo, J.A., Alfaro, M.J. \& Rocha, E. (1985a) Postoperative changes in the plasmatic levels of tissue-type plasminogen activator and its fast acting inhibitor: relationship to deep venous thrombosis and influence of prophylaxis. Thrombosis and Haemostasis, 54, 713716.

Páramo, J.A., Colucci, M., Collen, D. \& Van de Werf, F. (1985b) Plasminogen activator inhibitor in the blood of patients with coronary artery disease. British Medical Journal, 291, 573-574.

Rifón, J., Páramo, J.A., Prósper, F., Collados, M.T., Sarrá, J. \& Rocha, E. (1994) Thrombin-antithrombin complexes and prothrombin fragment $1+2$ in aorto-coronary bypass surgery: relation to graft occlusion. Hematologic Pathology, 8, 35-42.

Rocha, E., Alfaro, M.J., Páramo, J.A. \& Cañadell, J.M. (1988) Preoperative identification of patients at high risk of deep venous 
thrombosis despite prophylaxis in total hip replacement. Thrombosis and Haemostasis, 59, 93-95.

Rocha, E. \& Páramo, J.A. (1994) The relationships between impaired fibrinolysis and coronary heart disease: a role for PAI-1. Fibrinolysis, 8, 294-303.

Schneider, D.J., Nordt, T.K. \& Sobel, B.E. (1993) Attenuated fibrinolysis and accelerated atherogenesis in type II diabetic patients. Diabetes, 42, 1-7.

Schneiderman, J., Sawdey, M.S., Keeton, M.R., Bordin, G.M., Bernstein, E.F., Dilley, R.B. \& Loskutoff, D. (1992) Increased type 1 plasminogen activator inhibitor gene expression in atherosclerotic human arteries. Proccedings of the National Academy of Sciences of the United States of America, 89, 6998-7002.

Stalder, M., Hauert, J., Kruithof, E.K.O. \& Bachmann, F. (1985) Release of vascular plasminogen activator (v-PA) after venous stasis: electrophoretic-zymographic analysis of free and complexed v-PA. British Journal of Haematology, 61, 69-176.

Thompson, S.G. \& van de Loo, J.C.W. (1993) ECAT Angina Pectoris Study. Baseline associations of haemostatic factors with extent of coronary arteriosclerosis and other coronary risk factors in 3000 patients with angina pectoris undergoing coronary angiography. European Heart Journal, 14, 8-17. 